\title{
KAJI EKSPERIMENTAL TINGKAT KONSUMSI BAHAN BAKAR MINYAK SEPEDA MOTOR MANUAL TRANSMISSION DENGAN PENAMBAHAN BIOETHANOL
}

\author{
Muhammad Nur Ubaidillah*, Tabah Priangkoso, Darmanto \\ Jurusan Teknik Mesin, Fakultas Teknik, Universitas Wahid Hasyim \\ Jl. Menoreh Tengah X/22, Sampangan, Semarang 50236. \\ *Email: uillah147@gmail.com
}

\begin{abstract}
Abstrak
Keterbatasan bahan bakar fosil yang berasal dari minyak bumi mendorong penggunaan sumber energi terbarukan. Bioethanol merupakan salah satu sumber energi alternatif untuk bahan bakar yang dihasilkan dari tanaman dapat menjadi salah satu upaya untuk mengatasi masalah tersebut. Sepeda motor sebagai moda transportasi mayoritas di Indonesia masih bahan bakar minyak (BBM) sebagai sumber energi untuk penggerak. Penelitian ini bertujuan untuk mengetahui efek penambahan bioethanol pada bahan bakar minyak. Bioethanol sebesar 8\%, 10\%, dan 12\% akan digunakan untuk substitusi BBM jenis Pertalite, Pertamax dan Pertamax turbo. Pengujian dilakukan pada sepeda motor dengan transmisi manual pada 20 (dua puluh) kecepatan, dan 5 percepatan (gigi transmisi) untuk setiap jenis bahan bakar. Hasil penelitian menunjukkan bahwa konsumsi paling efisien didapat pada Pertalite dengan penambahan bioethanol 10\%, serta Pertalite dengan penambahan bioethanol 10\% mampu menempuh jarak $71.5 \mathrm{~km} /$.
\end{abstract}

Kata kunci: Bahan bakar kendaraan, Bioetanol, Efisiensi bahanbakar minyak

\section{PENDAHULUAN}

Di negara Indonesia hampir setiap orang menggunakan bahan bakar minyak gasoline produk Pertamina untuk mengisi kendaraan bermotor yang terdiri dari premium, Pertalite, Pertamax, dan Pertamax turbo. Bahan bakar tersebut memiliki nilai RON (Research Oktan Number) yang berbeda-beda yaitu premium dengan RON 88, Pertalite RON 90, Pertamax RON 92, Pertamax turbo RON 98. Untuk meningkatkan RON penelitian sebelumnya menggunakan zat aditif bioethanol sebagai pencampuran bahan bakar yang memiliki dampak positif baik dari emisi gas buang maupun kinerja mesin (PT. Pertamina, 2015).

Bioethanol yang berasal dari tumbuhtumbuhan diproses untuk membentuk aditif yang terbarukan atau menjadikan bahan bakar yang baik dan ramah lingkungan. Bioethanol dapat digunakan sebagai octane booster yang mampu menaikkan nilai oktan dengan dampak positif terhadap efisiensi bahan bakar dan menyelamatkan mesin. Bioethanol juga memiliki kandungan oksigen sehingga dapat digunakan dalam menyempurnakan proses pembakaran bahan bakar dengan efek positif dan meminimalkan pencemaran udara. Selain itu bioethanol berfungsi sebagai fuel extender, atau penghemat bahan bakar fosil (Prihandana dkk., 2007).

Kadar oktan yang dimiliki oleh bioethanol lebih tinggi jika dibandingkan dengan BBM yang ada dipasaran. Angka oktan bioethanol berada pada angka 108, jika bioethanol dicampurkan ke dalam bahan bakar minyak lainnya diharapkan mampu meningkatkan angka oktan pada bahan bakar tersebut. Peningkatan performa mesin dapat dicapai dengan mengetahui persentase pencampuran bioethanol yang tepat agar mesin melakukan pembakaran dengan baik dan sempurna (Cahyono, 2015)..

Berbagai jenis bahan bakar minyak untuk mesin gasoline banyak tersedia di pasaran. Sebagai contoh Pertalite, Pertamax dan Pertamax turbo. Pertamax merupakan jenis bensin tanpa timbal dengan RON 92 serta dianjurkan untuk kendaraan berbahan bensin dengan perbandingan kompresi tinggi (Winarno, 2011). Penelitian ini bertujuan untuk mengetahui pengaruh penambahan bioethanol pada sepeda motor 
dengan transmisi manual sebagai substitusi Pertalite, Pertamax dan Pertamax turbo.

\section{METODE PENELITIAN}

Penelitian ini menggunakan metode Ekperimental pada sebuah sepeda motor. Jenis sepeda motor sport 150 CC transmisi manual diuji tingkat konsumsi bahan bakar pada berbagai posisi gear transmisi. Empat jenis bahan bakar yaitu Premium, Pertalite, Pertamax 92, dan Pertamax Turbo. Keempat bahan bakar tersebut dicampur dengan bioethanol sehingga kandungan bioethanol adalah sebesar $0 \%, 8 \%, 10 \%$, dan $12 \%$ per liter pada setiap jenis bahan bakarnya (lihat tabel 1. Pengujian bahan bakar dilakukan sebanyak tiga kali untuk setiap jenis bahan bakar dan persentase campuran.

Tabel 1. Persentase Pencampuran Bahan Bakar

\begin{tabular}{|l|c|c|c|c|}
\hline \multirow{2}{*}{ Jenis BBM } & \multicolumn{4}{|c|}{ Kandungan Bioethanol (\%) } \\
\cline { 2 - 5 } & $\mathbf{0}$ & $\mathbf{8}$ & $\mathbf{1 0}$ & $\mathbf{1 2}$ \\
\hline Premium & $\checkmark$ & $\checkmark$ & $\checkmark$ & $\checkmark$ \\
\hline Pertalite & $\checkmark$ & $\checkmark$ & $\checkmark$ & $\checkmark$ \\
\hline Pertamax & $\checkmark$ & $\checkmark$ & $\checkmark$ & $\checkmark$ \\
\hline Pertamax Turbo & $\checkmark$ & $\checkmark$ & $\checkmark$ & $\checkmark$ \\
\hline
\end{tabular}

Pengujian terhadap setiap jenis bahan bakar dilakukan tiga kali, pada 20 (dua puluh) kecepatan dan 5 percepatan (gigi transmisi) yang berbeda sebanyak tiga kali. Selanjutnya dilakukan penghitungan ratarata dari pengujian tersebut untuk mendapatkan data yang akurat.

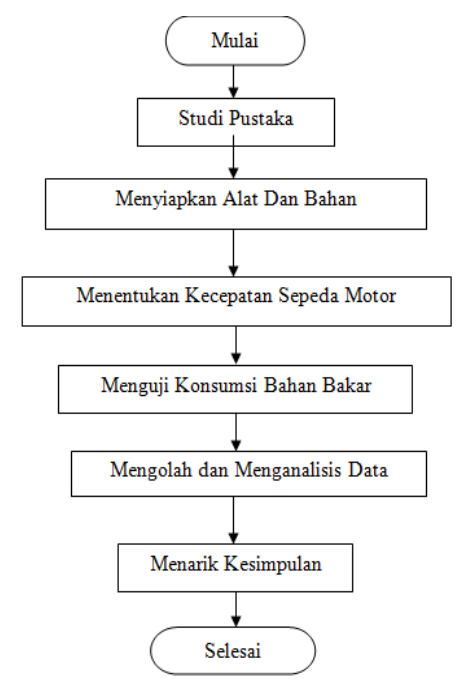

Gambar 1. Diagram alur penelitian

\section{HASIL DAN PEMBAHASAN}

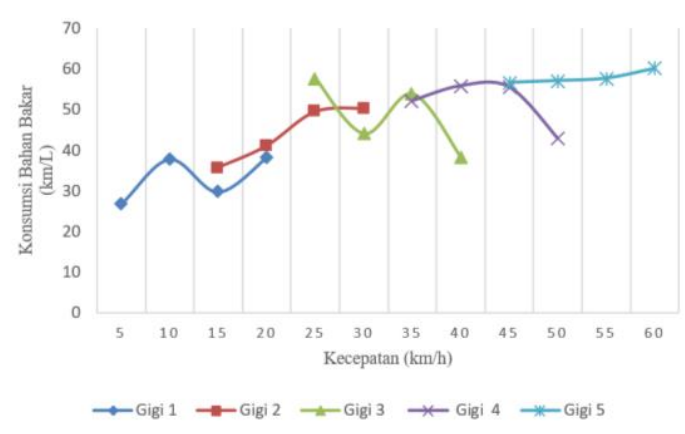

Gambar 2. Konsumsi Bahan Bakar Premium

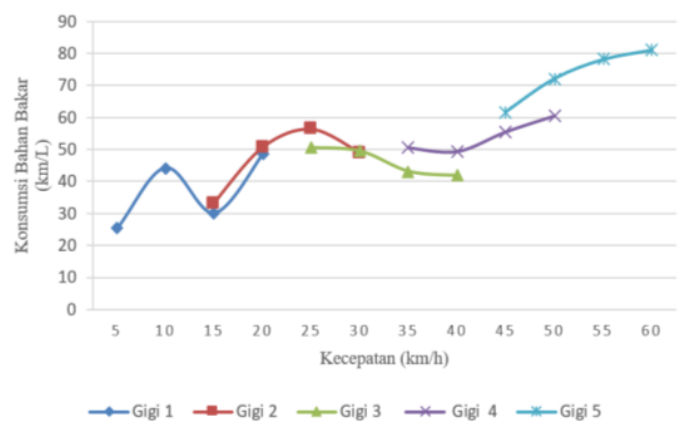

Gambar 3. Konsumsi Bahan Bakar Premium + bioethanol 8\%

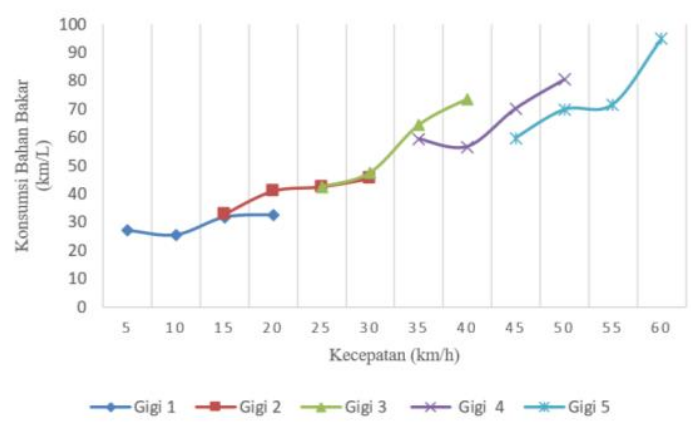

\section{Gambar 4. Konsumsi Bahan Bakar Premium + bioethanol 10\%}

Tingkat konsumsi BBM premium yang ditambahkan ethanol dapat dilihat pada gambar 2-5. Dari grafik tersebut terlihat perbedaan konsumsi sepeda motor uji jika diberikan tambahan ethanol sebanyak $8 \%$, $10 \%$ dan $12 \%$. Jarak yang mampu ditempuh premium murni setelah di rata-rata 46.986, Premium dengan bioethanol 8\% 51.571, Premium dengan bioethanol 10\% 
53.48, Premium dengan Bioethanol 12\% 50.274. Konsumsi bahan bakar paling hemat dihasilkan dari bahan bakar dengan penambahan bioethanol 10\%. Hal ini sesuai dengan penelitian terdahulu yang telah dilakukan (Wahminto dkk., 2019). Penelitian tersebut menguji konsumsi bahan bakar premium yang di campur dengan etanol sebanyak $8 \% 10 \%$ dan $12 \%$ dan di uji pada motor bertransmisi CVT 125 CC Fuel Injection system.

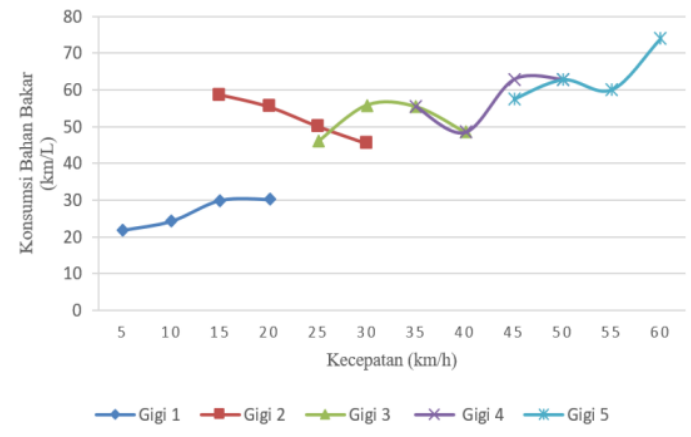

Gambar 5. Perbandingan Konsumsi Bahan Bakar Premium + bioethanol 12\%

Perbandingan tingkat konsumsi bahan Pertalite yang dicampur dengan sejumlah ethanol dapat dilihat pada gambar 6-9. Dari hasil gambar tersebut dapat dilihat bahwa tempuh meningkat hingga kandungan etanol 10\%, kemudian menurun pada kandungan etanol $12 \%$. Dengan demikian, secara umum kandungan etanol 10\% memberikan hasil terbaik dalam meningkatkan efisiensi dengan melihat jarak tempuhnya yang paling jauh untuk semua kecepatan dan untuk semua jenis bensin.

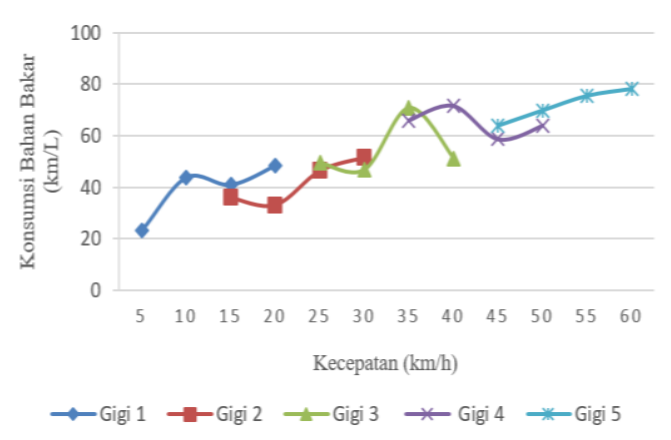

\section{Gambar 6. Perbandingan Konsumsi} Bahan Bakar Pertalite Murni

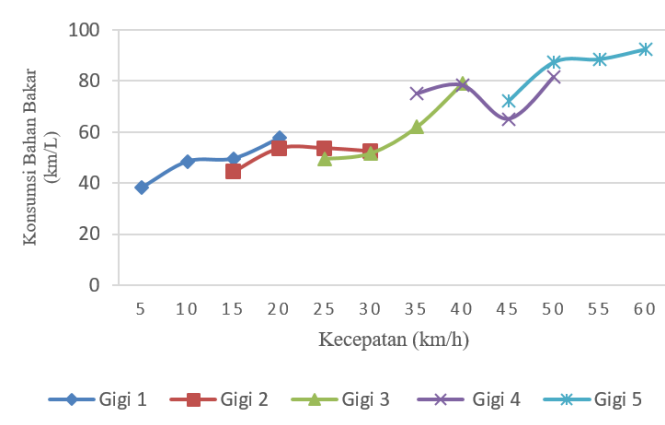

Gambar 7. Perbandingan Konsumsi Bahan Bakar Pertalite + Bioethanol 8\%

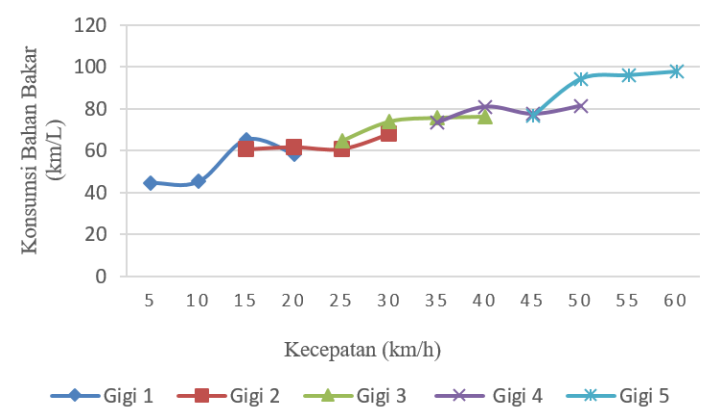

Gambar 8. Perbandingan Konsumsi Bahan Bakar Pertalite + Bioethanol 10\%

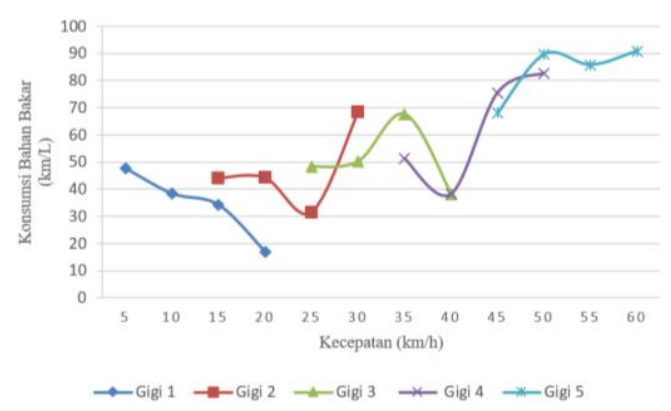

Gambar 9. Perbandingan Konsumsi Bahan Bakar Pertalite + bioethanol 12\%

Jarak yang mampu ditempuh premium murni setelah di rata-rata yaitu 54.475, Premium dengan Bioethanol 8\% 63.973, Premium dengan Bioethanol 10\% 71.596, Premium dengan Bioethanol 12\% 55.569. Konsumsi bahan bakar paling hemat dihasilkan dari bahan bakar dengan penambahan bioethanol 10\%. Hal ini sesuai dengan penelitian terdahulu yang telah dilakukan (Wahminto dkk., 2019). 
Penelitian tersebut menguji konsumsi bahan bakar premium yang di campur dengan etanol sebanyak $8 \% 10 \%$ dan $12 \%$ dan di uji pada sepeda motor $115 \mathrm{cc}$ FI bertransmisi CVT.

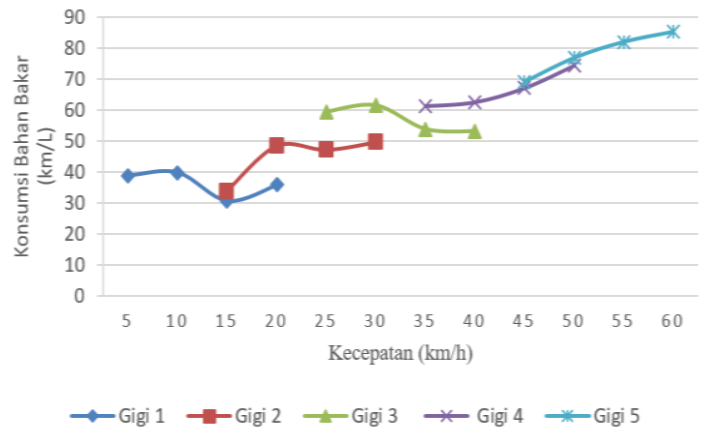

\section{Gambar 10. Konsumsi Bahan Bakar Pertamax Murni}

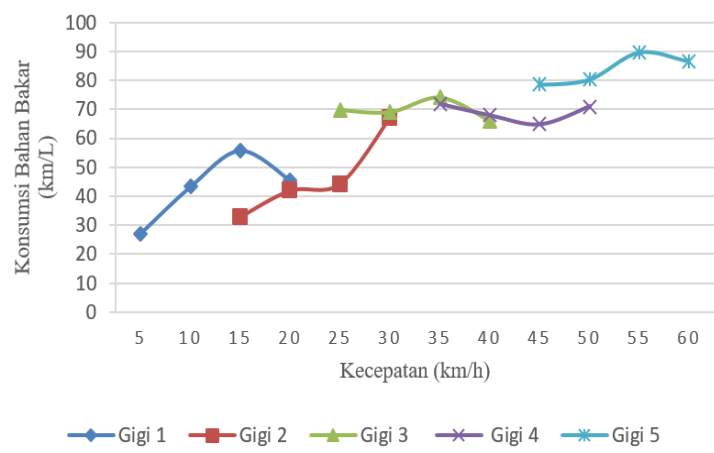

\section{Gambar 11. Konsumsi Bahan Bakar Pertamax + Bioethanol 8\%}

Tingkat konsumsi bahan bakar Pertamax yang dicampur dengan berbagai variasi kandungan bioethanol dapat dilihat pada gambar 10-13. Jarak yang mampu ditempuh Pertamax murni 0\% setelah di rata-rata yaitu 56.500, Pertamax 92 dengan Bioethanol 8\% 62.39, Pertamax 92 dengan bioethanol $10 \% \quad 68.308$, Pertamax 92 dengan bioethanol 12\% 62.006. Konsumsi bahan bakar paling hemat dihasilkan dari bahan bakar dengan penambahan bioethanol $10 \%$. Hal ini sesuai dengan penelitian yang telah dilakukan Aghus (2017). Penelitian tersebut menguji konsumsi bahan bakar premium yang di campur dengan etanol sebanyak $8 \% 10 \%$ dan $12 \%$ dan di uji pada sepeda motor $115 \mathrm{cc}$ FI bertransmisi CVT.

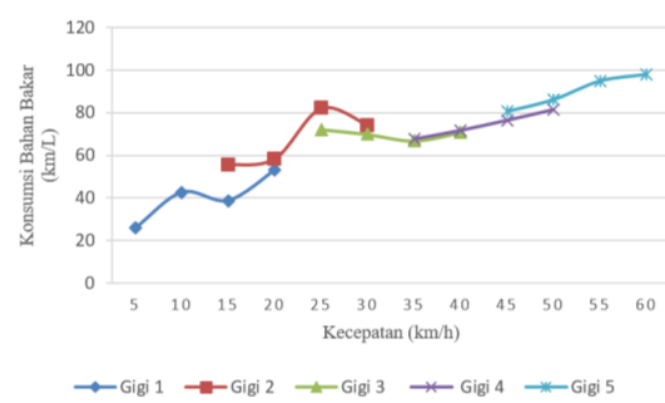

Gambar 12. bioethanol 10\% Pertamax

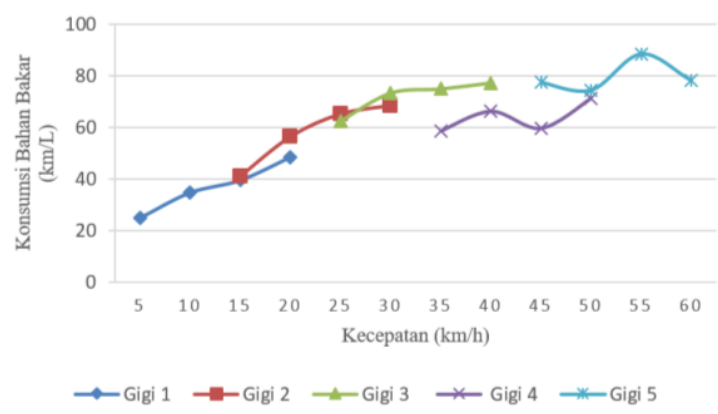

Gambar 13. Konsumsi Bahan Bakar Pertamax + bioethanol 12\%

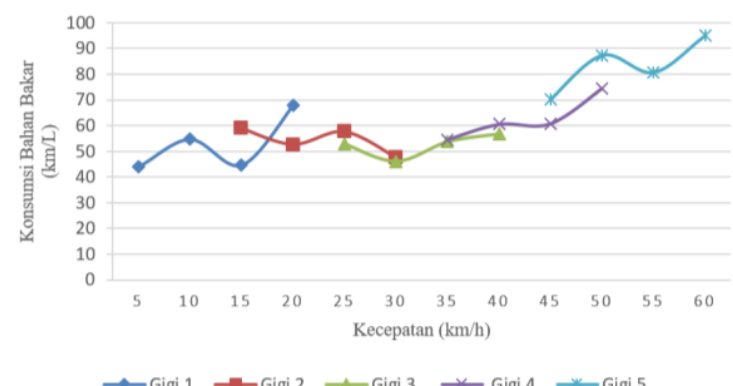

\section{Gambar 14. Konsumsi Bahan Bakar} Pertamax Turbo Murni

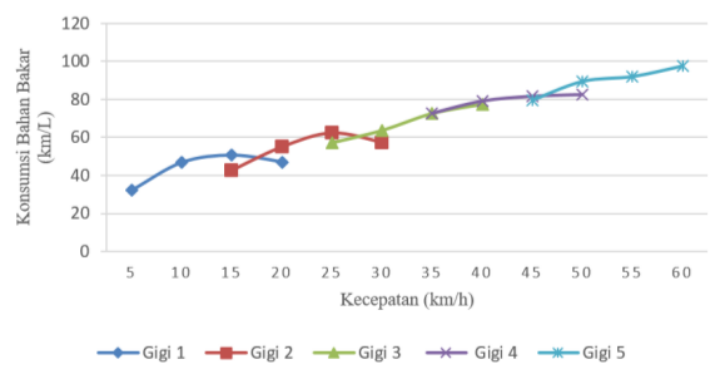

Gambar 15. Konsumsi Bahan Bakar Pertamax Turbo + bioethanol $8 \%$ 


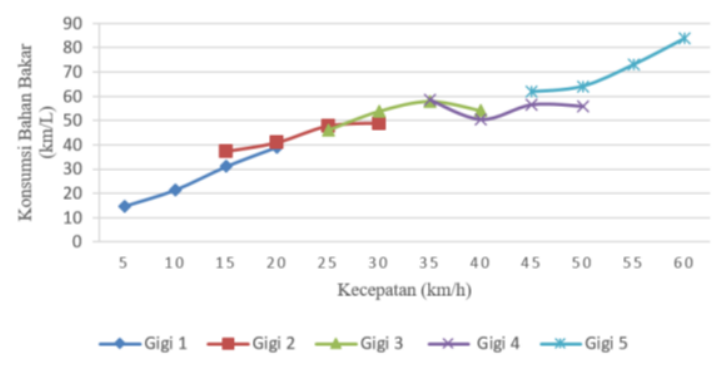

Gambar 16. Konsumsi Bahan Bakar Pertamax Turbo + bioethanol 10\%

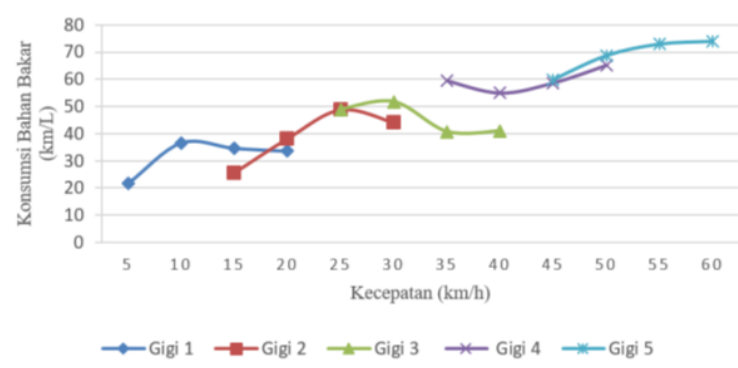

Gambar 17. Konsumsi Bahan Bakar Pertamax Turbo + bioethanol 12\%

Jarak yang mampu ditempuh Pertamax turbo murni $0 \%$ setelah di rata-rata yaitu 61.057, Pertamax turbo dengan bioethanol 8\% 66.958, Pertamax turbo dengan bioethanol 10\% 49.837, Pertamax turbo dengan bioethanol $12 \% \quad 48.941$. Konsumsi bahan bakar paling hemat dihasilkan dari bahan bakar dengan penambahan bioethanol $8 \%$.

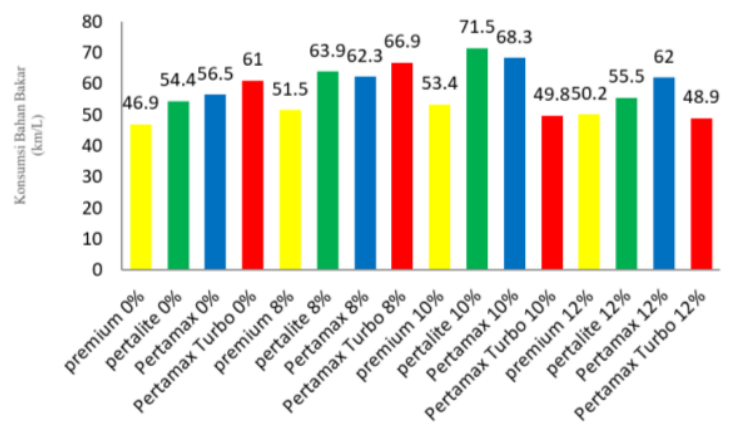

\section{Gambar 18. Perbandingan Rata-rata Konsumsi Bahan Bakar}

Dari hasil pengujian dan grafik konsumsi bahan bakar dengan penambahan bioethanol dapat disimpulkan bahwa Jarak yang ditempuh pada Pertalite penambahan bioethanol 10\% paling irit dibanding dengan bahan bakar murni dan bahan bakar dengan pencampuran penambahan bioethanol 8\%, dan $12 \%$, ini sesuai dengan penelitian yang telah dilakukan (Aghus,2017). Penelitian tersebut menguji konsumsi bahan bakar premium yang di campur dengan etanol sebanyak $8 \% 10 \%$ dan $12 \%$ dan di uji pada sepeda motor $115 \mathrm{cc}$ FI bertransmisi CVT.

\section{KESIMPULAN}

Hasil analisa pengaruh penambahan bioethanol terhadap konsumsi bahan bakar premium, Pertalite, Pertamax 92, Pertamax turbo terhadap konsumsi bahan bakar sepeda motor Yamaha V-IXION/FZ $150 \mathrm{cc}$ Tahun 2011 adalah konsumsi bahan bakar murni (yang belum dicampur dengan Bioethanol) Pertamax Turbo lebih menghemat bahan bakar, tetapi setelah ditambahkan bioethanol Pertalite dengan penambahan etanol $10 \%$ lebih menghemat bahan bakar dibandingkan dengan bahan bakar premium, Pertamax, Pertamax turbo.

\section{SARAN}

Untuk penelitian selanjutnya perlu dilakukan pengujian untuk mengetahui lebih lanjut pengaruh penambahan bioethanol terhadap konsumsi bahan bakar, diantaranya:

1. Pengujian emisi gas buang.

2. Pengujian dengan membandingkan rpm mesin.

3. Pengujian dengan menggunakan mesin DOHC.

4. Pengujian dengan menggunakan kecepatan maksimal sepeda motor.

\section{DAFTAR PUSTAKA}

Cahyono. (2015). Pengaruh Campuran Bioetanol Dengan Pertamax Terhadap Performa Mesin Motor 4. http://lib.unnes.ac.id/id/eprint/22739

Prihandana, R., Noerwijan, K., Adinurani, P. G., \& ... (2007). Bioetanol Ubi Kayu; Bahan Bakar Masa Depan. books.google.com.

https://books.google.com/books?hl=en $\& \mathrm{r}=\& \mathrm{id}=\mathrm{c} 48 \mathrm{yFkP} 1 \mathrm{eAgC} \& \mathrm{oi}=\mathrm{fnd} \& \mathrm{p}$ $\mathrm{g}=\mathrm{PA} 1 \& \mathrm{dq}=\mathrm{bioetanol}+\mathrm{ubi}+\mathrm{kayu}+\mathrm{bah}$ an+bakar+masa+depan\&ots $=-$ 
8KNldKPFp\&sig=v0i_zUBKIVO1Qq laih-Yk1J5brk

Wahminto, I., Priangkoso, T., \& Irsyad, A. N. (2019). Pengaruh Kandungan Ethanol Pada Bensin Terhadap Konsumsi Bahan Bakar Sepeda Motor EFI 115 CC dan 125 CC Bertransmisi CVT. Majalah, 8(5), 55. https://publikasiilmiah.unwahas.ac.id/i ndex.php/MOMENTUM/article/view File/3074/2971

Winarno, J. (2011). Studi Eksperimental Pengaruh Penambahan Bioetanol Pada
Bahan Bakar Pertamax Terhadap Unjuk Kerja Motor Bensin. Jurnal Teknik, 1 No 1, 33-39. 